\section{References}

Crisp, N. (2016) New global priority for mental health - reasons for optimism and concern. BJPsych International, 13(2), 27-29.

Erikson, E. (2014) Between Monopoly and Free Trade: The English East India Company, 1600-1757. Princeton University Press.

Kidd, C. (2016) Misappropriation. London Review of Books, 38(3), 17-18.

Lalvani, K. (2016) The argument: balance and perspective. In The Making of India: The Untold Story of British Enterprise, ch. 1 Bloomsbury.
Maughan, D. \& Burgess, D. (2016) Social sustainability and mental health: a threat to evidence-based practice? BJPsych International, 13(1), 4-5.

Pain, L. (2013) The golden age of maritime Asia. In The Sea and Civilization: A Maritime History of the World, ch. 13. Atlantic Books.

Taylor, D. J. \& Esmail, A. (1999) Retrospective analysis of census data on general practitioners who qualified in South Asia: who will replace them as they retire? BMJ, 318, 306-310.

West, M., Dawson, J. \& Kaur, M. (2016) Making the Difference: Diversity and Inclusion in the NHS. King's Fund.

\title{
MENTAL HEALTHLAW PROFILE \\ Mental health law in India: origins and proposed reforms
}

\author{
Muhammad Mudasir Firdosi ${ }^{1}$ and Zulkarnain Z. Ahmad ${ }^{2}$
}

'ST6 Specialist Registrar, South London and Maudsley NHS Foundation Trust, London, UK, email muhammad.firdosi@kcl. ac.uk

${ }^{2}$ Locum Consultant Psychiatrist, South West London and St George's NHS Trust, London, UK

\begin{abstract}
Although mental health legislation has existed in India since the mid-19th century, it has gone through various changes over the years and the Mental Health Care Bill 2013 has generated a lot of debate and criticism. Despite its shortcomings, the general expectation is that this bill will usher in a new era of proper care and allow people with mental disorders to lead a dignified life.
\end{abstract}

\section{Early legislation}

The first law in relation to mental illness in British India was the Lunatic Removal Act 1851, which ceased in 1891. This law was mainly enacted to regulate the transfer of British patients back to England. After the takeover of Indian administration by the British crown in 1858, many laws were introduced for the care of people with a mental illness, including:

- the Lunacy (Supreme Courts) Act 1858

- the Lunacy (District Courts) Act 1858

- the Indian Lunatic Asylum Act 1858 (with amendments passed in 1886 and 1889)

- the Military Lunatic Act 1877.

Under these acts, patients were detained for an indefinite period in poor living conditions, with little chance of recovery or discharge. This led to the introduction of a bill in 1911 that consolidated the existing legislation and led to the Indian Lunacy Act (ILA) 1912 (Somasundaram, 1987). The ILA 1912 was essentially the first law that governed mental health in India. It brought in fundamental change for the management of asylums, which were later termed mental hospitals. However, this act focused on the protection of the public from those who were considered dangerous to society (i.e. patients with a mental illness). The ILA 1912 neglected human rights and was concerned only with custodial sentences.
As a result, the Indian Psychiatric Society suggested that the ILA 1912 was inappropriate and subsequently helped to draft a mental health bill in 1950 (Trivedi, 2002).

It took more than three decades for this bill to receive the President's assent (in May 1987); it was finally implemented as an act in 1993. The advantage of the Mental Health Act (MHA) 1987 was that it defined mental illness in a progressive way, placing emphasis on care and treatment rather than on custody. It provided detailed procedures for hospital admission under special circumstances and emphasised the need to protect human rights, guardianship and the management of the property of people with a mental illness.

The criticisms of the MHA 1987 are mainly related to the legal procedures of licensing, admission and guardianship. Also, human rights and mental healthcare delivery were not adequately addressed in this Act (Narayan et al, 2011). Human rights activists have questioned the constitutional validity of the MHA 1987 because it involved the curtailment of personal liberty without the provision of a review by any judicial body. The MHA 1987 was also silent about the rehabilitation and treatment of patients after their discharge from hospital (Dhandha, 2010). In addition, insufficient treatment facilities posed financial, social and emotional burdens on carers and family. These criticisms led to the amendment of the MHA 1987, which eventually culminated in the Mental Health Care Bill 2013, which was introduced in the Rajya Sabha (upper house of parliament) on 19 August 2013. This bill repeals the MHA 1987, but is yet to come into force as an act. (The text of the bill is available at http://mohfw.nic.in.)

\section{Provisions of the Mental Health Care Bill (MHCB) 2013}

Under the MHCB 2013, every person shall have the right to access mental healthcare and treatment from services run or funded by the government. 
As such, a patient with mental illness will be able to access services and facilities such as: the provision of essential psychotropic medications, free of cost; insurance coverage for mental illness; funding for private consultation if a district mental health service is not available. The MHCB 2013 further ensures that treatment and rehabilitation will be available in the least restrictive environment and will respect the rights and dignity of patients, including those from disadvantaged socioeconomic backgrounds. The outcome of these recommendations is that the financial burden, as well as the psychosocial burden, placed upon carers will be reduced to a large extent (Gopikumar \& Parasuraman, 2013; Kala, 2013).

The MHCB 2013 introduces new concepts like advanced directives and nominated representatives, which allow individuals with mental disorders some autonomy over how they want to be treated in the future during periods of illness should they lose their ability (i.e. mental capacity) to make informed decisions, as well as over who their nominated representative will be to manage their affairs.

The bill requires the establishment of central and state mental health authorities. Also, every mental health establishment will have to be registered with the relevant central or state mental health authority.

A mental health review commissioning body will function as a quasi-judicial body to review periodically the use and procedures for making advance directives and will advise the government on the protection of rights of persons who are mentally ill.

Suicide is still a criminal offence in India, but this bill recommends its decriminalisation (Bhaumik, 2013). By decriminalising suicide, the stress resulting from social and legal causes can be minimised, which will not only reduce the burden on patients and carers but will also reduce the impact on the overburdened Indian legal system.

Finally, use of direct (unmodified) electroconvulsive therapy (ECT) is proposed to be banned (Narayanan et al, 2011). That is, ECT will be allowed to be used only with the use of muscle relaxants and anaesthesia. This therapy is prohibited for minors.

\section{Criticism of the MHCB 2013}

There are concerns that the new bill is too ambitious and unrealistic, given the lack of infrastructure, staff and resources, and may not therefore be able to deliver what is proposed (Antony, 2014). The average number of psychiatrists in India is only 0.2 per 100000 population, compared with a global average of 1.2 per 100000 population. Similarly, the figures for psychologists, social workers and nurses working in mental healthcare are 0.03 , 0.03 and 0.05 per 100000 population in India, compared with global averages of $0.60,0.40$ and 2.00 per 100000 , respectively (World Health Organization, 2005).
Secondly, this bill has an overinclusive definition of mental illness, which will have a significant impact on stigma. A better approach would be to have a precise and restrictive definition of mental illness because then the vast majority of patients would not have to face stigma-related problems (Antony, 2014).

The bill is not clear about the management of minors. A minor can be admitted only in exceptional circumstances, but these circumstances are not made entirely clear (Narayan et al, 2011).

In India, nearly half of all administrations of ECT are direct, which limits its use. Services are, though, being upgraded (Chanpattana et al, 2005; Gangadhar, 2013). Modified ECT is more expensive than direct ECT (Gangadhar, 2013) and anaesthetist back-up for psychiatric units is mostly not available yet. The positive outcome of this move could be a shift in the focus towards the development of better set-ups for modified ECT in the long term. Mobilising resources, greater public education, training of professionals and robust audit procedures should be urgent national priorities to help make the modified ECT available and accessible. This will address the concerns raised by various human rights organisations and will safeguard the rights of patients.

The bill decriminalises suicide but more as a stop-gap arrangement, by creating a presumption of mental illness in every case of attempted suicide unless proved otherwise. Suicide should be completely decriminalised, without any conditions attached, which would help reduce stigma, create openness and make it easier to seek help.

\section{Conclusion}

The MHCB 2013 is a step towards improving access to mental health services and bringing the law in line with international mental health legislation and human rights standards. The bill is a significant improvement over the existing MHA 1987, bringing about protection and empowerment of persons with mental illness. However, further discussion and debates are ongoing about its perceived shortcomings. Effective implementation will require a substantial change in the system currently in place and will need an extensive input of staff and finance. There are certain loopholes in the MHCB 2013 which question its applicability and meaningfulness for the Indian population. As admission procedures, treatment options and decision-making would become legalised and bureaucratised, certain experts are apprehensive that the bill will likely increase the stigma and hesitation to seek treatment from mental health professionals, due to cultural, educational and social factors, particularly in rural India. But at the same time, the revised legislation could mark a start of a new era for anti-stigma campaigns; it could lead to greater allocation of resources to mental health, and the training and retention of mental health professionals, including psychiatrists, psychiatric nurses and other allied professions. Hence, if appropriately implemented 
and financed, in addition to improved access to mental health services, the human rights of people who are mentally unwell could be safeguarded to a greater extent by the new act when it comes into power.

\section{References}

Antony, J. (2014) Mental Health Care Bill 2013: a disaster in the offing? Indian Journal of Psychiatry, 56(1), 3-7.

Bhaumik, S. (2013) Mental health bill is set to decriminalise suicide in India. BMJ, 347, f5349.

Chanpattana, W., Kunigiri, G., Kramer, B. A., et al (2005) Survey of the practice of electroconvulsive therapy in teaching hospitals in India. Journal of ECT, 21, 253-254.

Dhandha A. (2010) Status Paper on the Rights of Persons Living with Mental Illness in Light of the UNCRPD. In Harmonizing Laws with UNCRPD. Report prepared by the Centre of Disability Studies. Human Rights Law Network.
Gangadhar, B. N. (2013) Mental Health Care Bill and electroconvulsive therapy: anesthetic modification. Indian Journal of Psychological Medicine, 35, 225-226.

Gopikumar, V. \& Parasuraman, S. (2013) Mental illness, care and the bill: a simplistic interpretation. Economic and Political Weekly, 48(9), 69-73.

Kala, A. (2013) Time to face new realities: Mental Health Care Bill, 2013. Indian Journal of Psychiatry, 55, 216-219.

Narayan, C. L., Narayan, M. \& Shikha, D. (2011) The ongoing process of amendments in MHA-87 and PWD Act-95 and thei implications on mental health care. Indian Journal of Psychiatry, 53 , 343-350.

Somasundaram, O. (1987) The background of Indian Lunacy Act, 1912. Indian Journal of Psychiatry, 29, 3-14.

Trivedi, J. K. (2002) The mental health legislation: an ongoing debate. Indian Journal of Psychiatry, 44, 95-96.

World Health Organization (2005) Mental Health Atlas. WHO.
MENTAL HEALTHLAW PROFILE

\title{
Mental health law in Pakistan
}

\author{
Amina Tareen ${ }^{1}$ and Khalida Ijaz Tareen ${ }^{2}$
}

${ }^{1}$ Consultant Child and Adolescent Psychiatrist, Barnet, Enfield and Haringey Mental Health NHS Trust, UK, email aminatareen@ gmail.com

2Professor Emeritus, King Edward Medical University, Lahore, Pakistan; Co-Chairperson, Tareen Mental Health Foundation; Past President of the Pakistan Psychiatric Society, 1999-2001 We would like to thank Professor Syed Haroon Ahmed for information and advice provided.
Continued efforts to produce appropriate mental health legislation in Pakistan led to the Mental Health Ordinance of 2001. However, with the 18th amendment to the constitution and devolution of health responsibilities to the provincial governments, it became the task of the provinces to pass appropriate mental health legislation through their respective assemblies. Currently the mental health legislative picture is fragmented and unsatisfactory. Only the provinces of Sindh and Punjab have a mental health act in place and there is an urgent need for similar legislative frameworks in other provinces to protect the rights of those with mental illness.

\section{Background}

When Pakistan was created by the division of the Indian subcontinent in 1947, the newly created state continued with the Lunacy Act of 1912, which had been in place in British India. The focus of the act was more on detention than on treatment and with advances in treatment, especially the introduction of psychotropic medication, updated legislation was needed. In the 1970s and onwards, advocates for reform of this legislation were active. The government of Pakistan proposed a new mental health act in 1992 and circulated a draft among psychiatrists for their comments (Rehman, 1994) but it was not until 2001 that the Lunacy Act of 1912 was replaced by the Mental Health
Ordinance of 2001. A draft document was presented at the biennial conference of the Pakistan Psychiatric Society in Islamabad in 2001, attended by a number of UK psychiatrists, who, together with Pakistani psychiatrists, further shaped the draft. A large number of psychiatrists from Pakistan have been trained in the UK and the UK currently has a large number of British Pakistani psychiatrists who maintain strong links with psychiatry in Pakistan. Unsurprisingly, therefore, given these historical and ongoing links, the ordinance had significant similarities to the UK's Mental Health Act 1983.

The Mental Health Ordinance 2001 was in the form of a presidential order and set out to

'amend the law relating to the treatment and care of mentally disordered persons, to make better provision for their care, treatment, management of properties and affairs and to encourage community care and further to provide for promotion of mental health and prevention of mental disorder.' (Government of Pakistan, 2001)

The ordinance dealt with access to mental healthcare and voluntary and involuntary treatment. The duration of involuntary admission varied under different clauses. For instance, detention for assessment was for 28 days, detention for treatment was for 6 months, detention for the purposes of urgent admission was for up to 72 hours and emergency holding of a patient already in hospital could last 24 hours. The ordinance outlined processes by which patients had a right of appeal against their involuntary admission, which would be heard by the local magistrate, with applications made within 14 days of detention. Patients 